\title{
Postpartum psychosis: can it be prevented? A high-risk case report with a favorable outcome
}

\author{
Gustavo Carvalho de Oliveira ${ }^{1^{*}} \mid$ Amanda Cristina de Souza $^{2} \mid$ Ana Luiza Alves Nicoletti ${ }^{2}$ \\ Natália Mariana Diógenes da Silva de Albuquerque ${ }^{2}$
}

\begin{abstract}
${ }^{1}$ Associate Professor at Centro Universitário de Brasília (UNICEUB) - School of Medicine, Brasília, DF, Brazil. Adjunct Research Fellow at Swinburne University - Centre for Forensic Behavioural Science, Melbourne, VIC, Australia.

${ }^{2}$ Student undergraduate at Centro Universitário de Brasília (UNICEUB) - School of Medicine, Brasília, DF, Brazil.
\end{abstract}

\begin{abstract}
Introduction: postpartum psychosis is a rare psychiatric emergency that poses serious risks to both mother and child. Suicide and infanticide are the worst outcomes. Perinatal clinical and psychiatric examination is crucial in order to determine which patients are at high risk.

Case Report: A puerperal patient whose 23-day-old son was a wanted child from a planned pregnancy presented with behavioral changes that began seventeen days after the birth, including introversion, incoherent speech, soliloquy, and auditory hallucinations. She was into one of psychomotor agitation, irritability, and disorganized and hazardous behavior. At the diagnosis, she was suffering delusions of guilt and unfaithfulness. She was paranoid and negligent with her newborn. Previous psychiatric events appeared to be a manic episode. Pharmacological treatment resulted in full remission, and she was discharged from hospital.

Discussion: This condition is frequently overlooked due to its low incidence. This case report are suggestive of the need for greater observance during the perinatal period. Red flags include history of post-partum psychosis or bipolar disorder, clinical prodromal signs such as delirium, psychomotor agitation, and mental confusion, especially when social stress factors are present. Conclusion: A thorough medical evaluation is recommended in order to prevent risks and implement preventative treatment, such as Lithium Carbonate.
\end{abstract}

\section{1 | INTRODUCTION:}

$\mathrm{P}$ ostpartum psychosis is a psychiatric emergency that occurs in 1-2 cases per 1000 births. Symptoms usually peak within the first two to three weeks postpartum (Wesseloo et al, 2015; Ka- plan \& Soddock, 2017). Psychotic symptoms recur during the first year in $18-37 \%$ of cases (Camacho et al, 2016).

The causes of postpartum psychosis include physiological changes after giving birth, such as changes in hormone levels, in the immune system, and in 
the circadian cycle, in women who are susceptible to that condition (Bergink et al, 2016). Risk factors may be personal and or social. Personal, individual risk factors include obstetric events, first child, and a preexisting personal psychiatric history, particularly a previous diagnosis of bipolar disorder and or postpartum psychosis (Wesseloo et al, 2015) and a family history of psychiatric disorders. Social factors include expectations regarding socially accepted ideals regarding motherhood, family and societal demands and the inability to care for a newborn, as well as changes in family context and in female identity. Knowledge of the risk factors is important in disease prevention. Psychosis may or may not be preceded by a significant stress trigger, which in some cases may be identified by family or friends or others within the same cultural context (APA, 2013).

The clinical picture is one of agitation, insomnia, emotional lability, disorganized behavior, and mental confusion. At presentation, these may be prodromal to the psychotic state, the most important risks of which are suicide and infanticide (Cantilino, et al, 2016).

The dangerous nature of the postpartum psychotic condition warrants full clinical and psychiatric examination throughout pregnancy and puerperium, in order to identify mothers who are most susceptible to developing the condition, as well as assessing the risk-benefit ratio for pharmacological prevention with lithium during the postpartum period in the high-risk group. Consideration must be given to the potential loss in mother-child interaction due to psychosis.

Supplementary information The online version of this article (https://doi.org/10.15520/mcrr.v3i6.98 ) contains supplementary material, which is available to authorized users.

Corresponding Author: Gustavo Carvalho de Oliveira

Associate Professor at Centro Universitário de Brasília (UNICEUB) - School of Medicine, Brasília, DF, Brazil. Adjunct Research Fellow at Swinburne University Centre for Forensic Behavioural Science, Melbourne, VIC, Australia.

\section{I CASE REPORT:}

Thirty-eight-year-old female patient, married, 23 days postpartum, housewife, born in the State of Bahia, has lived in Brasilia, Brazil, for 26 years. She had three pregnancies, whose first birth, 19 years ago, was normal; the second pregnancy resulted in miscarriage, and the third 23 days ago by c-section due to placentary accretism, with no adverse incidents. She lives with her husband, children, mother in law, and a nephew. The family relations are healthy. She is the mother of a 19-year-old daughter and a 23day-old son, who was a planned and wanted child, especially after the miscarriage that terminated her second pregnancy.

The patient was seen in the emergency room of a general hospital in the Federal District. She was with her mother, who reported that 17 days after delivery the patient had begun to display altered behavior, becoming retracted and isolated. Over the next six days she developed psychotic symptoms, mainly isolating herself, and that over the following six days she had gotten worse, avoiding other people altogether, appearing confused, with soliloquy and auditory hallucinations. The hallucinations made her believe that a friend who was not present was calling her. Following that, and one day before our first contact with her, she had become agitated, irritated, and disorganized to the point where she became a risk to herself and to other people. Her hallucinations continued, and she went out into the yard and started running, screaming in apparent despair, and trying to leap over the wall around her house.

Upon psychiatric examination, she was oriented to self though not fully oriented to place, not recognizing the hospital she was in. She was hypotenacious and suspicious throughout the consult, displaying flat affect. She would speak loudly and then lower her voice, all the while in a normal rhythm. She was uncooperative, and revealed three delusional themes: the first was guilt, because she believed she was being negligent with her newborn and was not feeding him, which she thought was causing him to be underweight. The second type of delusion was persecutory, and she believed her husband was mistreating her by not letting her eat meat. The third type was a jealous delusion in which she thought her husband 
was cheating on her. All of these were denied by her mother, whose mental state was without alterations, which led us to believe that the patient's insight was poor.

Upon questioning the mother, we discovered the patient had Chagas'disease, and that she had a family history of depression (aunt and grandmother on father's side). No other psychiatric family history was mentioned. The mother informed the patient had learned to read and write poorly and had a hard time keeping up in school, often failing her subject matters. She said that in this pregnancy the patient had presented with bleeding that led to believe she could have another miscarriage, and this triggered a state of anxiety. Upon inquiry as to prior psychiatric events, she described an episode two years before with manic symptoms, such as unnecessary and excessive spending, and a lack of perceived need for sleep. She had recovered without treatment.

The patient was in the emergency room for twelve days, during which she gradually improved with the medication prescribed. This consisted of ferrous sulfate $1 \mathrm{~g}$ daily, haloperidol $2 \mathrm{mg} / \mathrm{ml} 20$ drops PO, levomepromazine $4 \% 25$ drops prn for insomnia or anxiety, sodium valproate $250 \mathrm{mg}$ bid. Upon release from the ER she was transferred to the infirmary for milk removal because of breast engorgement. The patient's behavior improved steadily. Upon release, her sleep and appetite were good, psychomotor agitation had ceased, humor was well modulated and her thought process was organized. The family was instructed as necessary and the patient was scheduled for ambulatory follow up. She was released from hospital on haloperidol $2 \mathrm{mg} / \mathrm{ml} 30$ drops a day and valproic acid $500 \mathrm{mg}$ a day.

\section{3 | DISCUSSION:}

Of the mental disorders that mothers may present with in the puerperium, postpartum psychosis is the most rare and most severe, with symptoms that are more serious than those of "baby blues" or postpartum depression (Wesseloo, 2015; Miranda et al, 2007). The clinical picture includes intense psychomotor agitation, delirium, detachment from reality, and mental confusion that begin two days to three weeks after birth (Miranda et al, 2007). Risk factors include altered hormones, immune system and circadian cycle, marital and financial changes, and a previous diagnosis of bipolar disorder and/or postpartum psychosis (Miranda et al, 2007). In patients with a history of bipolar disorder the incidence of postpartum psychosis is 260 cases per 1000 births (Camacho et al, 2016), which is some 200 times that of the overall population. The patient in this case presented with typical postpartum psychosis characteristics that appeared at the most frequent time described in scientific literature. She had important risk factors such as the risk of miscarriage, poor schooling, the ideal of motherhood imposed by society, and stress due to changes in family composition.

An early diagnosis of postpartum psychosis may be difficult, not only because it is rare, but also because of the diverse causes it may have. Psychosis may be divided into three types: endogenous, exogenous, and psychogenic. Postpartum psychosis may include any or all of these (Brockington et al, 2017). Along with the psychotic symptoms, patients may present with manic, depressive, or mixed symptoms (Camacho et al, 2016) and the intensity and course may fluctuate over time (Camacho et al, 2016; Brockington et al, 2017).

Postpartum psychosis warrants hospitalization due to the risk of suicide and infanticide (Miranda et al, 2007). Delusions usually involve the newborn (Camacho et al, 2016; Cantillo et al, 2010; Miranda et al, 2007). In the past, both of these risks were been overestimated, but today we know that in postpartum depression, suicide and infanticide occur in approximately $5 \%$ and $4,5 \%$ of cases, respectively, when there are psychotic symptoms present, and in less than one percent of cases when there are no psychotic symptoms. Forty-three percent of patients with postpartum psychosis suffer infanticidal delusions, and infanticide occurs mostly when the there is a perceived association between the newborn and religion, supernatural powers, or a congenital defect (Brockington et al, 2017). The patient in this case report presented with three types of delusions, in two of which she viewed herself as negligent, which aggravated her clinical picture. 
Postpartum infanticide is considered to be different from other crimes, and the most important features are the mother killing her own offspring; at birth or afterwards; and the influence of the postpartum state in which she may be. In this type of crime, specified under the article 123 of the Brazilian Penal Code, the mother may be sentenced to two to six years in prison (Moreira et al, 2017). Neuroscientific studies show, however, that these women need treatment rather than punishment in order to curb further fatalities related to their condition (Camacho et al, 2016).

The chief risk factors for postpartum psychosis are a previous diagnosis of bipolar disorder and a history of postpartum psychosis in previous pregnancies. The prophylactic use of lithium, usually prescribed in the postpartum period - despite studies that support its use during pregnancy, may be instituted concomitantly with breastfeeding. Although one fourth of the mother's blood levels may be transmitted to the fetus, recent studies have failed to find adverse effects in the newborn (Wesselo et al, 2017). Nonetheless, mother and child must be followed up with regular lithium blood levels, as well as thyroid and kidney function monitoring, in order to avoid lithium intoxication (Wesseloo et al, 2017; Pacchiarotti et al, 2016; Vigueira et al, 2007).

Treatment for postpartum psychosis is expected to achieve full remission of symptoms, and consists of psychiatric hospitalization, the use of typical or atypical antipsychotics, and electroconvulsive therapy, accompanied by family and individual psychoeducation ${ }^{2}$. The patient in this case report was hospitalized and received medication, which contributed to her gradual improvement and release. A detailed assessment during prenatal follow-up, with the knowledge of and further description of her possible history of bipolar disorder with a manic episode two years prior could have led to better management of the case in the peripartum, and it is possible that the episode could have been detected earlier on and the symptoms avoided or reduced.

\section{4 | CONCLUSION:}

Given that postpartum psychosis is a serious - albeit rare - mental disorder of the postpartum pe- riod, the clinician must be aware of the clinical and psychiatric assessment required to assess risk factors for this condition and be able to establish an early and adequate diagnosis. Observation and anamnesis including risk factors, especially a history of bipolar disorder or previous episode of postpartum psychosis, and psychoeducation for the mothers at greater risk and their families, constitute an effective way of avoiding the disorder and its serious consequences for mother and child. Suicide, infanticide, and aggression against the newborn can thus be reduced.

\section{5 | REFERENCES:}

American Psychiatric Association-APA (2013). Diagnostic and statistical manual of mental disorders: DSM-5. Arlington: American Psychiatric Publishing.

Camacho RS, Cantinelli FS, Ribeiro CS, Cantilino A et al (2016). - Transtornos psiquiátricos na gestação e no puerpério: classificação, diagnóstico e tratamento. Archives of Clinical Psychiatry 33;2, 92-102.

Bergink V, Rasgon N, Wisner KL (2016). Postpartum Psychosis: Madness, Mania, and Melancholia in Motherhood. American Journal of Psychiatry;173(12):1179-88.

Bergink V, Bouvy PF, Vervoort JS et al (2012). Prevention of postpartum psychosis and mania in women at high risk. American Journal of Psychiatry;169(6):609-15.

Brockington I (2017). Suicide and filicide in postpartum psychosis. Archives of women's mental health.;20(1):63-9.

Cantilino A, Zambaldi CF, Sougey EB et al (2010). Transtornos psiquiátricos no pós-parto. Archives of Clinical Psychiatry;37:288-94.

Kaplan H \& Sadock B (2017). Compêndio de Psiquiatria. 11 ed. Porto Alegre: Artmed.

Miranda AM, Garcia APM, Carvalheira EA (2007). Levantamento das necessidades emocionais das mães e educadoras de crianças de zero a dois anos. Revista tecnico-cientifico das faculdades atibaia $\mathrm{p}$. 11-25. 


\section{MANUSCRIPT CENTRAL}

Moreira AFG, Ribeiro MVP (2017). A (in) existencia do estado puerperal de acordo com a medicina forense. Boletim Informativo Criminologico. p. 10919.

Pacchiarotti I, León-Caballero J, Murru A et al (2016). Mood stabilizers and antipsychotics during breastfeeding: focus on bipolar disorder. European Neuropsychopharmacology, v. 26, n. 10, p. $1562-$ 1578.

Viguera AC, Newport DJ, Ritchie J, et al (2007). Lithium in breast milk and nursing infants: clinical implications. American Journal of Psychiatry, v. 164, n. 2, p. 342-345.

Wesseloo R, Wierdsma AI, van Kamp IL et al (2017). Lithium dosing strategies during pregnancy and the postpartum period.The British Journal of Psychiatry, v. 211, n. 1, p. 31-36.
Wesseloo R, Burgerhout KM, Koorengevel KM et al (2015). [Postpartum psychosis in clinical practice: diagnostic considerations, treatment and prevention]. Tijdschr Psychiatr;57(1):25-33.

\section{Acknowledgements:}

Miles Castedo Forrest, who was very kind to translate this article.

How to cite this article: Oliveira G.C., Souza A.C., Nicoletti A.L.A., Albuquerque N.M.D.S. Postpartum psychosis: can it be prevented? A high-risk case report with a favorable outcome. Journal of Medical Care Research and Review. 2020;369-373. https://doi.org/ $10.15520 /$ mcrr.v3i6.98 